\title{
REFLEXÕES ACERCA DA BONECA INDÍGENA: EDUCAÇÃO ESCOLAR, DIVERSIDADES E INFÂNCIAS
}

\section{REFLECTIONS ABOUT THE INDIGENOUS DOLL: SCHOOL EDUCATION, DIVERSITY AND CHILDHOODS}

\section{REFLEXIONES SOBRE LA MUÑECA INDÍGENA: EDUCACIÓN ESCOLAR, DIVERSIDAD E INFANCIA}

\section{Ana Cláudia Magnani Delle Piagge}

Mestranda no Programa de Educação Sexual. Pedagoga, Artesã, Escritora, Contadora de História e Investigadora das Artes Manuais. Pesquisadora e colaboradora do AKOMA Grupo de Estudos e Pesquisas em Africanidades, Culturas, Diversidades \& Memórias/CLADIN-LEAD-NUPE da UNESP-FCLAr

E-mail: anaclmagnani@gmail.com

\section{Marcia Cristina Argenti Perez}

Doutora em Ciências, concentração em Psicologia, pela Universidade de São Paulo (USP-FFCLRP). Docente e Pesquisadora da Universidade Estadual Paulista Faculdade de Ciências e Letras, Departamento de Psicologia da Educação (UNESP FCLAr). Líder do GEPIFE: Grupo de Estudos e Pesquisas sobre Infância, Família e Escolarização

(UNESP-CNPq).

E mail: marciacap@fclar.unesp.br.

Tatiane Pereira de Souza

Doutora em Ciências Sociais pela Programa de Pós-Graduação em Ciências Sociais (UNESP/FCLAr). Mestre em Educação pela UFSCar. Pedagoga e Congadeira do Terno de Congada Chapéus de Fitas. Idealizadora e Coordenadora do AKOMA: Grupo de Estudos e Pesquisas em Africanidades, Culturas, Diversidades \& Memórias/CLADIN-LEAD-NUPE da UNESP-FCLAr.

E-mail: tatiane.akoma@gmail.com

\section{RESUMO}

De que forma, crianças que não veem bonecas semelhantes aos marcadores da diversidade de identificações étnico raciais, poderão construir a sua identidade, desenvolvendo sua alteridade, e, consequentemente, a aceitação do outro, constituindo-se, assim, como pessoas plenas, que reconhecem a diversidade de identidades corpóreas? Essa indagação ilustra nosso incomodo com a ausência de bonecas que representem as diversidades socioétnicorraciais e culturais presentes na sociedade. Por isso, o objetivo desse trabalho é sistematizar conhecimentos e estratégias sobre a utilização da boneca indígena Rtixòkò. A metodologia utilizada é de cunho bibliográfico e transdisciplinar realizada a partir da análise de estudos da área da História, Sociologia e Psicologia da Educação e obras específicas da cultura indígena. 
O estudo permitiu sistematizar conhecimentos que legitimam a importância da boneca, como símbolo lúdico e cultural relevante na sensibilização das crianças quanto a diversidade étnica existente no Brasil, a partir do conhecimento da história e da cultura.

Palavras-chave: Identidade. Crianças. Brincadeiras com bonecas.

\begin{abstract}
In what way, children that do not see dolls with similar markers of the diversity of ethnic racial identities, could build your identity, develop your otherness, and consequently acceptance of the other, and consequently, constitute this way like a person that recognize the diversity of corporeal identities? This Indignation show our discomfort with the absence of dolls that represent the diversity of social ethnic racial and cultural present in our society. That's why the goal of this work is to systematize knowledge and strategies about the utilization of indigenous dolls Rtixòkò. The methodology used is bibliographic and multidisciplinary made from analyze of the studies in the area of History, Sociology and Education Psychology and specific works made by the indigenous culture. The study allowed to systematize knowledge that legitimize the importance of the dolls as a simbol ludic and relevant in the awareness raising as to the ehtnic diversity present in Brazil, from the knowledge of history and cultura.
\end{abstract}

Keywords: Identity. Children. Play with dolls.

\title{
RESUMEN
}

De qué manera, los niños que no ven muñecas similares a los marcadores de la diversidad de identidades étnicas raciales, pueden construir su identidad, desarrollar su alteridad y, en consecuencia, la aceptación del otro, constituyéndose así como personas plenas, que reconocen la diversidad de las identidades corporales? Esta pregunta ilustra nuestra incomodidad con la ausencia de muñecas que representan la diversidad socio-étnica y cultural presente en la sociedad. Por lo tanto, el objetivo de este trabajo es sistematizar el conocimiento y las estrategias sobre el uso de la muñeca Rtixòkò indígena. La metodología utilizada es bibliográfica y transdisciplinaria basada en el análisis de estudios en el área de Historia, Sociología y Psicología Educativa y trabajos específicos de cultura indígena. El estudio permitió sistematizar el conocimiento que legitima la importancia de la muñeca, como un símbolo lúdico y cultural relevante en la conciencia de los niños sobre la diversidad étnica existente en Brasil, a partir del conocimiento de la historia y la cultura.

Palabras clave: Identidad. Niños. Juega con muñecas.

\section{INTRODUÇÃO}

No Brasil, ainda persiste uma triste realidade, que, apesar de ter sido constituído a partir da presença e participação de culturas diversas, que contribuíram para o desenvolvimento desta nação, ainda é comum perceber uma gama de estereótipos e preconceitos que afetam o imaginário social e coletivo, com relação a produção dessas culturas. É fato que, convivemos num país multicultural, no qual, a diversidade e a diferença que fazem dele rico e único, não são reconhecidas e respeitadas como deveriam ser, no ग) 
sentido da ética e do respeito à vida, e, a perspectiva, segundo a cosmovisão de mundo desses povos. De um lado, temos a diversidade e a multiculturalidade, informando o cotidiano e a cultura de muitos brasileiros, por outro lado, temos o desconhecimento da diversidade cultural que informa nosso modo de ser, pensar, comer, andar, sentir e criar. O povo brasileiro se alimentou e se alimenta das diferenças presentes neste território, ao mesmo tempo que desvaloriza e discrimina essas diferenças, que são as características de nossa riqueza cultural e imaterial (SOUZA, 2012).

O brincar com bonecas proporciona à criança a oportunidade de explorar as diferenças, aprendendo a apreciá-las, fazendo-as se educar num contexto de brincadeiras. $\mathrm{O}$ brincar com bonecas, dentro do ambiente escolar, contribui para desenvolver na criança, sua formação identitária, sua identidade corporal, assim como desenvolver sua alteridade. De acordo com Kishimoto (2017) o ambiente escolar, carrega em si uma composição diversa, no qual inúmeras marcas identitárias se mesclam e se misturam, ainda traz o fardo de ser um espaço no qual, a discriminação e a exclusão, infelizmente, encontra-se presente.

Para Vera Candau a escola tem urgência em trabalhar com questões que sejam relacionadas ao reconhecimento e a valorização de diferentes culturas, isto é, "incorporar a perspectiva intercultural nos diferentes âmbitos educativos" (CANDAU, 2012, p. 237). Para atingir esse intento, a escola deve propiciar a criança conteúdos e atividades que favoreçam o entendimento das diferenças a partir das relações de alteridade e com isso facilitar o processo de constituição da identidade de si e do outro.

Apesar da sociedade contemporânea se constituir num contexto de intolerâncias, cujo diálogo entre o eu e o outro tem se tornado cada vez mais difícil, a escola torna-se um espaço propício para que essa temática seja abordada, justamente por abranger em seu interior a diversidade expressa entre os recortes sociais, tais como o étnico, o cultural, de gênero, as deficiências, dentre outros. Assim, na sociedade existe a crença, embasada pela intolerância e pelo preconceito de que é o outro o responsável por todos os problemas, por todos os males que afligem a sociedade e, portanto, depositários das falhas sociais. O Outro nesse sentido, são aquelas pessoas cujas situações de suas vidas marcadas pela opressão discriminatória são atribuídas a elas próprias, dizendo de outro modo, o discurso do senso comum torna as próprias vítimas em algozes.

É a partir deste tipo de crença que os estigmas sustentam-se em pensamentos do imaginário popular, em que se entende que o problema da pobreza é o pobre, que o problema 
do racismo são os negros ou os indígenas, que o machismo é problema das mulheres, que a violência é gerada por indivíduos violentos, em os problemas de aprendizagens manifestados pelos alunos é problema da criança e assim por diante. A tendência desses tipos de afirmação é camuflar as discussões, as responsabilidades e as oportunidades de ampliar a consciência e buscar soluções. A cultura que se mantém nesse tipo de afirmação é a cultura do conformismo, o qual se localiza um culpado e exclui a responsabilização de debater o problema desde sua origem, fortalecendo assim rótulos e estereótipos.

A escola é o espaço em que esse tipo de percepção da realidade deveria ser combatido. Por mais que seja a escola uma instituição do Estado, ela deve priorizar debater temas cuja multiculturalidade de um país esteja presente, desde a escolha e composição curricular até as práticas e posturas pedagógicas. O que se vê na maioria das vezes, ainda é a reprodução das bases preconceituosas, racistas e discriminatórias da sociedade. A escola como espaço social, ao invés de reproduzir, deveria debater, dialogar sobre. A escoa que falamos é a escola composta por pessoas. A escola é o conjunto de pessoas que tem, pelo menos de maneira formal, o intento de educar. É nisso que acreditamos.

Nesse sentido, entende-se que a escola deva trazer para dentro de sua rotina o diálogo sobre a alteridade, para a partir dele não somente ampliar os horizontes, mas para contribuir na formação de indivíduos que reconheçam o "eu" e o "outro" como sendo diferentes, nem superiores, nem inferiores, apenas diferentes, tendo suas culturas e características corporais como elementos que favoreçam o respeito e a "construção de igualdades" (CANDAU, 2012, p.239).

No entanto, para que a escola alcance esse modelo de ensino multidisciplinar, intercultural e humanizador, se faz necessária a presença de pedagogos preparados para lidar com essas temáticas a partir dos confrontos que os diálogos possam enfrentar. E esses estejam preparados não para lidar com superficialidade, mas, para ir além do senso comum com processos educativos que tenham em seu cerne a articulação entre equidade e diferença, fazendo aproximações, tecendo provocações que levem aos alunos a pensar, refletir, apreender. Isso só é possível não somente pela sensibilização aos temas e as diferenças, mas pelo processo formativo quer seja institucional ou pessoal. Conforme Vera Candau: 
Hoje não é possível trabalhar questões relacionadas à igualdade sem incluir a questão da diferença, nem se pode abordar a questão da diferença dissociada da afirmação da igualdade. De fato, a igualdade não está oposta à diferença, e sim à desigualdade, e diferença não se opõe à igualdade e sim à padronização, à produção em série, à uniformização (CANDAU, 2012, p. 239).

Então, essa é a proposta desta pesquisa, na qual, a partir da utilização de um recurso pedagógico, a construção de bonecas Rtixòkò, buscamos apresentar a cultura indígena, suas diferenças culturais em relação as práticas e visões de mundo, tendo "suas diferenças reconhecidas como elemento de construção da igualdade" (CANDAU, 2012). Incentivando ações como estas, procuramos promover dentro do espaço escolar, uma luta contra todo tipo de ensino que produza padronização e desigualdade.

Pois a questão central a ser apresentada às crianças, a partir deste trabalho é: Somos iguais ou somos diferentes? O direito a diferença e a valorização das diferenças culturais é, certamente, um assunto a ser discutido pela escola e, segundo Candau, a questão da diferença, na contemporaneidade, tem assumido uma importância especial, tornando-se um direito. "Direito dos diferentes a serem iguais" e "Direito de afirmar a diferença em suas especificidades" e particularidades (CANDAU, 2012, p. 240).

Portanto, visamos por meio da sistematização de conhecimentos do brincar com bonecas indígenas, que carregam em si marcas identitárias de uma cultura, proporcionar à criança a apropriação de qualidades humanas, como a alteridade e a empatia, que são externas à elas no momento de seu nascimento, e que, por meio das atividades vividas coletivamente serão por elas apropriadas. Pois, o composto dos estudos realizados sob o enfoque da psicologia histórico-cultural indica ser uma exigência para que ocorra essa máxima apropriação das qualidades humanas, por parte das crianças pequenas, que elas tenham a possibilidade de exercer suas formas específicas de atividades, como: a atividade com objetos, o tateio, a comunicação entre crianças, entre elas e os adultos e, o brincar exercitando os jogos de papeis sociais.

Os jogos protagonizados e/ou brincadeira de papéis sociais, para Elkonin (1987), são atividades que produzem na criança um impacto direto, criando a oportunidade de experimentar o mundo adulto, travando uma direta relação com a atividade humana, e das relações entre estas, desenvolvendo assim suas percepções do que é ser humano e de estar integrado a uma sociedade rica em contrastes e contradições. Assim como, as atividades humanas trazem o crivo da história, para o autor, brincadeira também trará. Para Arce e RELEDUC | ISE | v. 2 | n. 2 | ago. 2019 
Simão, Elkonim, por meio de seus estudos, confirma a importância do jogo para o desenvolvimento psicossocial da criança.

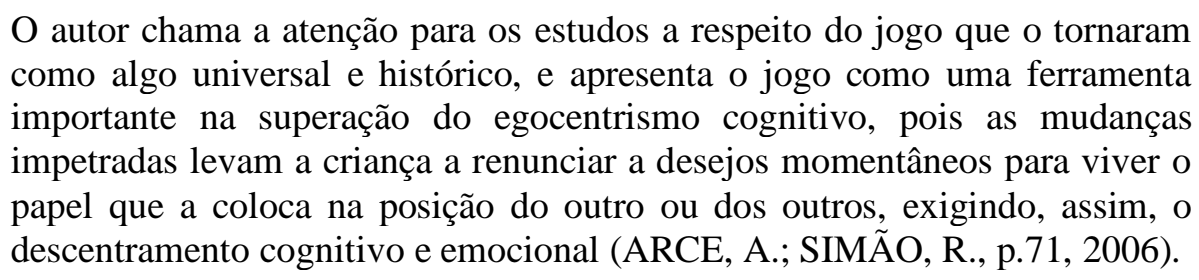

A atividade humana, no caso da criança menor de 6 anos, os jogos de papéis sociais, inserida em um meio social, desenvolve o processo de formação da psique infantil. Segundo Elkonin (1987) através das interações sociais a criança se forma como indivíduo experimentando e confrontando o externo a si, distinguindo àquilo que ela não é, assim, a criança consegue estabelecer o que ela é a partir do contraste identitário. Ademais, no brincar com bonecas, a criança experimenta tanto suas relações com um mundo direto e familiar, como pode experimentar o contato com culturas diversas, quando à ela é possibilitada a oportunidade de manuseio de objetos, bonecas, que contenham marcadores de outras identidades culturais.

Para Elkonin (1987), no desenvolvimento da atividade do jogo de papeis sociais, acontece uma importante transformação psíquica na criança, e esta é fundamental para o seu desenvolvimento. Contudo, para o autor, torna-se incontestável a relação entre adulto e criança, durante o andamento da atividade do brincar, para que esse desenvolvimento ocorra. Apesar de manipular o objeto, ou seja, a boneca, como forma de interagir com o mundo, a apropriação das qualidades humanas por parte da criança, se dará a partir da relação desta com outros humanos, seja através da observação, seja através da interação. Desta forma, a criança, mediada por um adulto, se desenvolve a partir da apropriação de sua humanidade. Vygotsky afirma que a criança aprende a ser humana interagindo com outros seres humanos.

Temos a crença, infundada, que o brincar é inerente à criança, sendo este mesmo brincar, motivo de liberdade para ela, sendo necessário somente que esta deixe fluir livremente sua imaginação para que a brincadeira ocorra. Em outras palavras, acredita-se que a criança deverá ser deixada livre para que assim possa fazer sua fantasia brotar. Essa crença traz em si uma contradição ao afirmar ser o brincar, uma atividade livre por parte da criança. Para Arce e Simões, "o jogo é uma atividade que possui uma finalidade e um resultado a ser atingido" (ARCE; SIMÃO, 2006, p. 72). 
Elkonin (1987) ressalta que esta crença traz o paradoxo fundamental do jogo: por um lado, é uma atividade livre, embora ancorada em emoções; por outro, é fonte de desenvolvimento do caráter voluntário e da tomada de consciência, pela criança, de suas ações e de seu ser. Vygotsky (1933) auxilia na elucidação deste paradoxo ao afirmar que o jogo satisfaz certas necessidades infantis e motivações que se encontram na esfera afetiva. Essas motivações e necessidades apresentam-se na tentativa da criança de realizar desejos impossíveis de serem atendidos; para tanto, ela recorre a imaginação, mais precisamente ao uso da situação imaginária. É essa situação que permite a ela, durante a brincadeira, assumir, por exemplo, o papel da mãe, da professora, do motorista de ônibus, ou seja, realizar ações do mundo adulto que lhe são inacessíveis no momento. Entretanto, essa situação imaginária, por mais que pareça libertar a criança do real, permitindo que ela assuma papeis distintos do seu ser, não o faz, pois contém regras implícitas para sua realização. O próprio papel assumido impõe regras, assim, não há como a criança agir em uma situação imaginária sem regras. 'A situação imaginária sempre possui regras'.

A criança, para desenvolver a brincadeira deverá seguir as regras, socialmente impostas, para o papel que ela deseja experimentar. Como o conteúdo utilizado nesta brincadeira são as atividades e relações humanas, e essas se desenvolvem de acordo com a realidade e a cultura, com a qual a criança mantenha relações, ou, que a ela seja apresentada; a mediação do adulto, se faz necessária, para que ela aprenda a manipular os objetos durante a brincadeira e dar uma função social a eles. Sem a ajuda do adulto, a criança não será capaz de utilizar os objetos; necessitando para realizar isso, a mediação de um adulto que lhe sirva de modelo, para ela imitar. Elkonin afirma que "o desenvolvimento das ações com os objetos é o processo da sua aprendizagem sob a direção imediata dos adultos" (ELKONIN, 1987, p. 216)

Dentro do ambiente escolar, mediado pelo pedagogo, a criança alcançará seu pleno desenvolvimento através da utilização dos jogos protagonizado e/ou de papeis sociais, bastando que ao pedagogo se ater a implicação histórico-social do processo. Portanto, a escola, cumprindo seu papel humanizador, deve estar atenta ao papel a ser desempenhado pelo pedagogo junto às crianças e ao conteúdo que por ele será transmitido, servindo de modelo para que a criança imitar.

Para Elkonin (1998) a educação das crianças é um problema que a sociedade deve levar a sério, como forma de enfrentar todos os problemas que impactam à elas. Problemas de ordem econômica, política e social podem ser minimizados por uma educação que proporcione um desenvolvimento adequado à criança; e isso, pode ser conseguido através da utilização consciente e adequada dos jogos protagonizados dentro das instituições escolares. 
Arce e Simão (2006) nos alertam sobre os problemas que podem ser gerados pela falta de mediação dos adultos, nos momentos de desenvolvimento das brincadeiras, e pela falta de apresentação de novas temáticas, deixando que a criança fique sempre protagonizando as mesmas brincadeiras, impedindo-a de ampliar seu conhecimento de mundo. Para elas, Elkonin (1998) enfatiza a importância da preocupação da sociedade com a educação de suas crianças, em especial no desenvolvimento dos jogos protagonizados, pois para o autor:

Quando não se aborda essa questão indo às raízes, para além das aparências, corremos o risco de atribuir um caráter alienante para esta atividade infantil, enquadrando-a como parte do mundo infantil, mundo à parte, ambiente fechado isolado da sociedade. Esta atitude talvez explique, segundo o autor (1998) a falsa impressão que temos da existência de um mundo infantil especial que nos impede de agirmos para promover o desenvolvimento das crianças, dando ao adulto o papel de destaque que este possui (ARCE; SIMÃ̃O, 2006, p.86).

Para cumprir seu papel humanizador, e proporcionar à criança uma educação de qualidade, que promova nela, seu melhor desenvolvimento, deve ser dada especial atenção ao conteúdo que será trabalhado, de forma a proporcionar à criança acesso a temáticas que vão além do seu mundo, ampliando sua cultura, tornando à elas possível aprender e compreender, sobre homens e sociedades, que não estejam no seu trato diário. Estas ações contribuirão para a formação integral deste indivíduo.

Além disto, a escola, cumprindo seu papel de educar à criança deve primar por assumir a sua responsabilidade em romper com os paradigmas referentes à imagem do indígena para que se possa criar relações positivas, reconhecendo e valorizando esses povos, sua história e sua cultura, dentro do ambiente escolar.

Nesse sentido, a Lei n 9.394/96 Lei de Diretrizes e Bases da Educação Nacional, alterada pela Lei $\mathrm{n}^{\mathrm{o}} 10.645 / 03$, posteriormente complementada pela Lei 11.645/08 torna obrigatória a inserção do ensino de História e Cultura Africana, Afro-Brasileira e Indígena nos currículos escolares. Contudo, é sabido que a ação pedagógica calcada na implementação da lei por parte da escola e do educador, quando engajada, contribui para a construção da identidade da criança que se dispõe a aprender com a cultura de um grupo étnico diferente do seu, ampliando seu universo de possibilidades, nesse sentido, não é somente a criança que aprende com a cultura indígena, os professores também aprendem e ter a oportunidade de repensar diferentes modos de ser, estar e compreender o mundo oriundos das culturas 
indígenas, africanas e afro-brasileiras. Sendo assim, "não é possível se trabalhar questões relacionadas à igualdade sem incluir a questão da diferença” (CANDAU, 2012, p.239).

Paulo Freire (1996; 2005), Vera Maria Candau (2008; 2011) por meio de seus estudos, nos alertam sobre a necessidade da escola promover uma cultura que busque respeitar as diferentes histórias e culturas oriundas dos povos que compuseram este país. Freire (1999) e Bosi (1992) chamam atenção para a necessidade de uma convivência respeitosa entre as diferentes culturas no Brasil, visando à superação das assimetrias e hierarquias. Nessa direção, no caso da América Latina e particularmente do Brasil, trazer a interculturalidade como perspectiva teórica nos permite olhar de maneira mais equânime às relações mantidas entre diferentes pessoas e comunidades que compõem o continente e o país. Pois, a interculturalidade, enquanto concepção, diz respeito a grupos sociais e a relação entre diferentes gerações e, pode contribuir para entender grupos étnicos que ao se reconhecerem nas suas diferenças se unem e buscam uma valorização, respeito e compreensão recíproca. Estes grupos, buscam reivindicar e exercer o direito a diferença contra o preconceito e discriminação, seja qual for à natureza. Buscam também o aproximar-se entre culturas, para dialogar e realizar trocas, conhecimentos e aprendizagens (CANDAU, 2008a e 2008b).

Segundo Kishimoto (2017) o nosso enraizamento cultural, tem a ver com as redes de significado e sentido produzidas pela coletividade social. Tanto as bonecas, quanto as brincadeiras, reproduzem padrões sociais, que como construções sociais advêm das relações entre as pessoas e o mundo. Num mundo eurocêntrico, percebe-se que a maior parte das bonecas que são produzidas pela indústria de brinquedos são de características, brancas e loiras, excluindo de sua produção características ruivas, orientais, indígenas e negras.

Esta observação nos levou ao questionamento do porquê da pequena, para não dizer inexistente, produção de bonecas de etnias diversas, em um país em que toda essa diversidade está presente, numa profusão sígnica e multicultural.Constatamos, a partir desta observação, que boa parte das crianças tem acesso a um único tipo de boneca, com características das etnias europeias, produzindo uma invisibilização das diferenças. Dentro de um processo pedagógico, esse tipo de atitude nega e silencia outras culturas, transformando todo o processo em uma profusão monocultural. Isso, diretamente afetará a formação da criança, tornando-a um indivíduo incapaz de reconhecer e aceitar as diferenças culturais presentes no seu dia-a-dia. 
Para Kishimoto (2017), certamente, estas crianças encontram dificuldades na construção de sua alteridade, sendo conduzidas à negação das características inerentes a cada um, a reproduzir estereótipos e percepções preconceituosas devido ao acesso a um único tipo de boneca. As crianças precisam se ver representadas nas bonecas, e precisam ter contato também com bonecas que representem o "outro". A boneca, portanto, ao nosso ver, além de ser um importante recurso lúdico, é um meio de construção da identidade da e na criança, capaz de propiciar à ela possibilidades de fantasiar, experimentar e recriar a realidade e o mundo por meio da brincadeira, promovendo assim, a sua formação identitária e sua alteridade.

Mas, é necessário ir além, apresentando a criança, a cultura que essa boneca representa. Portanto, trazer a boneca Rtixòkò, ou boneca Karajá, envolvida em enredos de contação de histórias e de brincadeiras, protagonizadas pelas crianças, pode sim contribuir para o desenraizamento de práticas ofensivas à diversidade. Trazer essas bonecas envolvidas em novas narrativas e formas de brincar, pode e muito contribuir para que as crianças reconheçam que existem diferentes formas de ser, num determinado corpo, numa determinada cultura, geração e classe social, e que isso faz dela um ser humano que merecesse ser respeitado como tal.

O estudo das bonecas Rtixòkò é nosso objeto de trabalho e que, possibilitará nos possibilitará apresentar à criança o indígena brasileiro, fazendo-a conhecer esses povos, histórica e culturalmente, rompendo com os paradigmas referentes a essa temática. Com isso, esperamos construir na criança, sua percepção sobre as diferenças e igualdades, desenvolvendo sua alteridade, fazendo-a apreender sua identidade, rompendo com as imposições sociais e culturais instituídas pela sociedade.

\section{RTIXÒKÒ: A BONECA DE BARRO KARAJÁ}

Considerada, desde 2012, um patrimônio imaterial do povo brasileiro, as bonecas de cerâmica, da etnia Karajá, denominadas Ritxòkò (fala feminina) e Ritxoo (fala masculina), foram reconhecidas pelo IPHAN - Instituto do Patrimônio Histórico e Artístico Nacional, graças ao trabalho desenvolvido pelo Museu Antropológico da Universidade Federal de Goiás (UFG). A boneca Ritxòkò, é o símbolo da identidade cultural do povo do Karajá. Representam as cenas do cotidiano na aldeia e os ciclos dos rituais. Essas bonecas são 
utilizadas para educar as crianças e ocupam um lugar fundamental na transmissão da cultura milenar do povo Karajá.

Mais do que objetos meramente lúdicos, essas bonecas são representações culturais que comportam significados sociais profundos, reproduzindo o ordenamento sociocultural e familiar dos Karajá. Com motivos mitológicos, de rituais, da vida cotidiana e da fauna, são importantes instrumentos de socialização das crianças que se veem nesses objetos e aprendem a ser Karajá, recebem ensinamentos, aprendem as técnicas e saberes associados à sua confecção e usos. Por representarem cenas do cotidiano e dos ciclos rituais, elas portam e articulam sistemas de significação da cultura Karajá e, dessa forma, são lócus de produção e comunicação dos seus valores (IPHAN, 2014)

Enquanto as mulheres confeccionam as bonecas, as meninas Karajá brincam em seu entorno, observando os adultos fazerem as bonecas, desta forma, as crianças são educadas na cultura rica deste povo ao mesmo tempo que "aprendem as técnicas e saberes associados à sua confecção e usos" (IPHAN, 2014). Essa boneca, para o povo Karajá vai muito além da sua utilização como brinquedo, pois a sua confecção e manuseio estão associados a significação da cultura, de forma que esse objeto transcende a mera qualificação como lúdico e transforma-se em um agente de transmissão dos valores e do modo de vida da cultura Karajá. Através das bonecas de cerâmica, as mulheres Karajá representam o mundo material e simbólico do povo Iny, por meio da arte de modelagem da argila e da decoração das peças (MA, 2014). Temos que compreender, as bonecas Rtixòkò, como "representações culturais que comportam significados sociais profundos, reproduzindo o ordenamento sociocultural, e familiar dos Karajá" (IPHAN, 2014). Brincando, a criança se reconhece na boneca e aprende a ser Karajá.

Para compreender mais profundamente o significado da educação da criança para os grupos indígenas brasileiros, e mais especificamente, o povo da etnia Karajá devemos compreender o que, para eles, significa educar a criança, e qual é o espaço ocupado por ela, dentro da sociedade indígena. Segundo nos explica Daniel Munduruku:

[...] as crianças ocupam um lugar privilegiado na sociedade indígena. Desde que nascem são tratadas de uma forma muito carinhosa. [...] As crianças que mamam ficam sempre junto de suas mães. Se choram, são acalentadas imediatamente e logo lhes é dado de mamar. [...] Se a mãe vai para a roça, ela o leva consigo; se vai tomar banho no rio, lá estará o bebê. [...] O pai também se sente responsável pelo filho ou pela filha. Sempre que não está fora, em caça, fica pertinho deles, brincando na rede. Essa é uma maneira de o pai ajudar a mãe na educação dos filhos menores. É claro que muita gente ajuda a olhar as crianças: os irmãos e primos maiores, os tios e os avós. (MUNDURUKU, 2012, p.48-49).

64

RELEDUC | ISE | v. 2 | n. 2 | ago. 2019 
Na sociedade indígena, em geral, a criança é preciosa e "todos" são responsáveis por ela. A vida em sociedade se diferencia dos povos colonizadores, no sentido de que os povos indígenas viverem sempre de forma coletiva. As crianças estão sempre junto aos adultos e, sua aprendizagem procede do observar, ver, imitar, fazer junto. Existe a cultura de levar à sério a criança, e essas podem participar da vida social da comunidade, aprendendo, na prática, como devem se comportar de acordo com a situação. Em muitas ocasiões, não é permitido a criança fazer determinadas coisas, mas elas estão sempre por perto, observando, aprendendo. Nesses momentos, após a saída dos adultos, as crianças ocuparão seu lugar, fazendo do seu jeito, o que observaram os adultos fazerem. Outras vezes, enquanto os adultos fazem por exemplo panelas, as crianças, a partir da observação, e com instrução dos adultos próximos, fazem panelinhas. Então, segundo Munduruku, "tudo que o adulto faz, a criança pode brincar de fazer" e completa dizendo que "é claro que na vida das crianças também há o ensino formal, quando ficam atentas ao que os mais velhos tem para contar, porque a sabedoria está com eles" (MUNDURUKU, 2012, p.50).

No Brasil, hoje, o número de povos indígenas chega a 215; com 180 línguas indígenas, distintas entre si, pertencentes a troncos indígenas diferentes. Alguns povos já mantem contato com os não índios, e já acabaram por incorporar elementos culturais à sua cultura, como: roupas, instrumentos, remédios, e outros que vivem em estado de isolamento, sobre os quais pouco, ou quase nada se sabe. Alguns povos falam, também o Português, outros também sabem falar o idioma dos povos vizinhos. No Nordeste, alguns povos passaram por tal repressão cultural, proibidos de falar sua língua, que acabaram por perde-la. Restando apenas poucas palavras de sua língua natal.

A nação indígena é parte integrante da nação brasileira e por esse motivo são detentores de direitos e de deveres. Existe uma "legislação indigenista" que assegura, aos povos indígenas, uma proteção especial, por respeito a sua cultura diferente do resto das culturas do país. Essa é a forma, do Estado brasileiro, reconhecer os direitos dos povos indígenas, primando pela manutenção de suas terras, que são parte principal para a sua manutenção física e cultural, como forma de manter viva suas tradições, seus usos e seus costumes. 
A terra é fundamental para a sobrevivência física, cultural e espiritual dos povos indígenas. Índio e terra são uma mesma coisa, uma coisa única. Não é possível sobreviver sem ela. No entanto, essas populações têm sofrido vários ataques no elemento unificador de sua cultura, porque muitos interesses são contrários à manutenção das terras indígenas. (MUNDURUKU, 2012, p.29).

Existem muitas nações indígenas, no território brasileiro, cada uma com sua cultura e, torna-se impossível falar sobre essas culturas de forma generalizada. Por esse motivo, ao tratarmos sobre a boneca indígena, escolhemos uma, da cultura do povo Karajá, para desenvolver esse trabalho. Mas, o que quisemos demonstrar com a breve explanação sobre os povos indígenas foi alertar para a necessidade de que o pedagogo que se propuser a incluir em seu conteúdo, as bonecas Rtixòkò, como forma de trabalhar com as crianças a temática indígena, antes deve ter o cuidado de incluir, em sua preparação, leituras que lhe proporcionem o conteúdo necessário a ser transmitido. A legislação nos traz, na Lei 11.645/08, a obrigatoriedade de trabalhar em sala de aula a temática indígena, mas, a consciência de trabalhar adequadamente, e com coerência, essa temática, isto, deve vir de cada pedagogo, mas não somente, a implementação da LDB é uma questão de lei, uma questão burocrática e institucional, quem não cumpre a determinação da lei maior da educação sofre com as penalidades jurídicas que lhe cobra e posiciona as devidas responsabilidades. Mais do que trazer a boneca indígena para dentro do ambiente escolar, queremos através do brincar com bonecas, apresentar ao professor e, consequentemente, a criança a cultura indígena, visto a importância que o vivenciar tem para a formação contínua de todos.

\section{MODELAGEM COM ARGILA PARA CRIANÇAS}

Trabalhar com o barro para os povos indígenas é parte da sua cultura, uma técnica desenvolvida para preencher a necessidade de se alimentar, e a transmissão ocorre sempre dentro da sociedade indígena, partindo das gerações mais velhas para educar as gerações mais jovens.

Vale a pena saber que não há especialistas entre os nativos: todos sabem confeccionar os objetos necessários à sua sobrevivência. $\mathrm{O}$ que existe são pessoas que se destacam em um ou outro tipo de objeto utilitário ou artístico, devido ao talento pessoal (MUNDURUKU, 2012, p.53).

Esse é um trabalho essencialmente feminino, pois cabe às mulheres da tribo coletar o melhor barro, fazer as misturas necessárias sendo com tipos diferentes de barros, folhas, 
cerâmicas partidas ou carvão, tudo moído e incorporado ao barro, na medida certa para conseguir a melhor elasticidade. Cada povo tem a sua receita, seu modo de fazer incorporado por sua cultura e as mulheres sabem fazê-lo, pois aprendem desde cedo.

Para realizar a coleta, as mulheres, acompanhadas pelas meninas, vão para a beira de rios, procuram o melhor barro, testam sua textura, pois suas mãos já estão acostumadas com seu tato. Ali, mostram o barro às meninas, fazendo-as toca-lo, para que estas aprendam a reconhecer o melhor barro. Coletam esse barro e o carregam para a aldeia. Ali procedem as misturas apropriadas, para que ele se torne adequado à modelagem. Não existe uma única formula para a mistura, mas são distintos de acordo com a cultura e os recursos materiais existentes. Também se diferem às práticas da modelagem, da queima e da pintura. Cada etnia tem o seu saber e sua arte. As artes gráficas elaboradas nas peças também são diferenciadas, pois "são referências culturais que transcendem o espaço das aldeias e apresentam-se como identificação do território e da cultura regional” (IPHAN, 2014).

Não são todos os povos que decoram suas peças com grafismos, isso difere de acordo com as marcas da cultura, que esse povo quer transmitir. Mas sempre a inspiração vem da natureza, afirma Daniel Munduruku, pois para os povos indígenas essa "é a fonte incansável de inspiração às criações artísticas de homens e mulheres" (MUNDURUKU, 2012, p.52). As bonecas Rtixòkò, por exemplo, está entre as inúmeras expressões culturais materiais da confeccionadas pela etnia Karajá. Essas bonecas:

[...], além de obra artística primorosa originada das mãos leves das ceramistas, constituem uma referência significativa do grupo. Confeccionadas em cerâmica, pintadas com uma grande diversidade de grafismos e representando tanto as formas humanas como as da fauna regional, são artefatos que singularizam o Povo Karajá diante dos demais grupos indígenas brasileiros e sul-americanos (IPHAN, 2014)

Então, existem formas distintas associados a Ritxòkò ou Ritxoo, que incluem desde a coleta e preparação das matérias primas, modos de fazer e usos, que podem ser desde cotidianos como lúdico-educativos, como no caso das bonecas; também temos que levar em consideração as transformações que foram ocorrendo nestas bonecas ao longo do tempo, assim bem como o lugar que elas ocupam na rede de relações sociais e simbólicas do povo Karajá e desta com os demais segmentos da sociedade nacional (MA, 2014). 
Para os povos indígenas do brasil, de maneira geral, não existe uma diferença ou limite preciso entre arte e objetos utilitários (como uma ferramenta ou uma panela), uma vez que tudo garante as necessidades da vida cotidiana, ritual e artística (MUNDURUKU, 2012, p.52).

$\mathrm{Na}$ educação infantil, é difícil encontramos uma criança que tenha dificuldade no manuseio do barro, e as qualidades plásticas deste contribuem, nesse sentido, por não impor nenhum tipo de restrição às possibilidades de criação. Por sua constituição, extremamente maleável, permite às crianças só através da utilização das mãos, criarem formas infinitas e depois de secas, serem pintadas de forma eficiente.

A criança, ao manusear o barro, dentro do ambiente escolar, está se apropriando de cultura, como também, está se tornando uma produtora de cultura. A criança pequena produz cultura? Temos que entender que tudo aquilo que um indivíduo produza, independentemente da idade deste, será um reflexo daquilo a que este sujeito teve acesso, seja através do ouvir, do ver ou do perceber. "O processo de ensino, portanto, não é contrário ao processo de criação, mas condição deste. O ensino é fonte de aprendizagem, que, por sua vez, é fonte do desenvolvimento do psiquismo, em geral, e da criatividade, em particular" (SACCOMANI, 2016, p.172). A apropriação, por parte da criança, do fazer a boneca Karajá, promoverá nela a possibilidade de aproximação da cultura indígena, produzindo aprendizagens.

Então, no que diz respeito apresentar a cultura indígena, através de oficinas de confecção de bonecas Karajá, utilizando o barro como matéria prima, essas oficinas proporcionaram à criança a oportunidade de desenvolver sua alteridade, enquanto processo humanizador, mas, também, desenvolver sua criatividade enquanto processo de formação psíquica.

No que diz respeito à formação psíquica da criança, temos que entender que a criatividade não é inerente ao sujeito, nem surge da consciência de modo natural e espontâneo. "A criatividade como fenômeno presente na vida de todos os seres humanos apenas se desenvolverá se for formada por meio de processos educativos que visem essa formação" (SACCOMANI, 2016, p.172).

Conclui-se que a modelagem de barro é muito importante para desenvolver a criatividade da criança, além de trabalhar a coordenação motora fina dela. Amassar o barro e dar-lhe forma exigirá da criança a utilização de gestos naturais, que influenciaram prontamente a coordenação de seus movimentos. Além disto, através da apropriação de uma 
nova cultura, a criança modelará imagens no barro, que produziram nela a apropriação de sua alteridade.

\section{BREVES CONSIDERAÇÕES FINAIS}

Entender a educação a partir dessa pluralidade de culturas, nos ajuda a criar ambientes educativos mais dinâmicos e, sobretudo, mais abertos e plurais. A diversidade contribui para a excelência de processos educativos nas práticas sociais e pedagógicas, por gerar espaços de convivência que possibilitam tornar a escola um espaço que assuma as diferenças existentes, construa relações novas e que sejam verdadeiramente igualitárias, compreender valores, que podem fortalecer e potencializar a condução da vida. No entanto, criar oportunidades de aprendizagens e ensinamentos por meio de bonecas plurais, oportunizam a construção do respeito a diversidade e à diferença a partir da ludicidade e das brincadeiras.

Mais que trazer a boneca indígena para dentro do ambiente escolar, queremos através do brincar com bonecas, apresentar a criança a cultura indígena, visto a importância que o vivenciar tem para a formação da criança. Diante de tudo que foi exposto espera-se contribuir para o debate sobre as possibilidades pedagógicas de trabalhar a cultura indígena e suas dimensões no currículo escolar, enfatizando não somente os diversos aspectos da história e cultura dos povos indígenas no Brasil, mas também criando pedagogias, posturas e processos educativos que oportunizem a desconstrução dos estigmas sociais sobre esses povos. É necessário estar atento para não reproduzir ideais desumanizadoras, sobretudo, hierárquicas sobre essas culturas enfatizando acima de tudo sua grande contribuição e participação no desenvolvimento e identidade nacional.

\section{REFERÊNCIAS}

ARCE, Alessandra; SIMÃO, Rosimeire. A psicogênese da brincadeira de papeis sociais e/ou jogo protagonizado na psicologia do jogo de D. B. Elkonin. In: ARCE, Alessandra; DUARTE, Newton (org.). Brincadeiras de papeis sociais na educação infantil: as contribuições de Vigotsky, Leontiev e Elkonin. São Paulo: Xamã, 2006. 120 p.

Museu Antropológico. Universidade Federal de Goiás. Bonecas Karajá. Disponível em: https://museu.ufg.br/p/1322-bonecas-karaja. Acesso em 09.Jan. 2018

BROUGERE, Gilles. A criança e a cultura lúdica. Rev. Fac. Educ., São Paulo, v. 24, n. 2, p. 103-116, julho 1998. Disponível em: 
http://www.scielo.br/scielo.php?script=sci_arttext\&pid=S010225551998000200007. Acesso em 01.Mar.2017.

CANDAU, Vera Maria. Direitos humanos, educação e interculturalidade: as tensões entre igualdade e diferença. Revista Brasileira de Educação. v. 13 n. 37 jan./abr. 2008a. Disponível em: http://www.scielo.br/pdf/rbedu/v13n37/05. Acesso em 17. maio. 2017. A diferença está no chão da escola (2008b) In: Anais IV Colóquio Lusobrasileiro sobre Questões curriculares e VIII Colóquio sobre Questões Curriculares. Florianópolis: Universidade Federal de Santa Catarina.

Diferenças culturais, cotidiano escolar e práticas pedagógicas. Currículo sem Fronteiras, v.11, n.2, pp.240-255, Jul/Dez 2011. Disponível em: http://www.curriculosemfronteiras.org/vol11iss2articles/candau.pdf. Acesso em 12.jul.2017. Diferenças culturais, interculturalidade e educação em direitos humanos. Educ. Soc., Campinas, v.33, n.118, p.235-250, jan./mar. 2012. Disponível em http://www.cedes.unicamp.br. Acesso em: 20.Out.2017

FREIRE, Paulo. Pedagogia do Oprimido. 46.ed. Rio de Janeiro: Paz e Terra, 2005.

GEERTZ, Clifford. A interpretação das culturas. Rio de Janeiro: Livros Técnicos Científicos, 1989.

INSTITUTO DO PATRIMÔNIO HISTÓRICO E ARTÍSTICO NACIONAL. RTIXòKò: EXPRESSÃO ARTÍSTICA E COSMOLÓGICA DO POVO KARAJÁ. DISPONÍVEL EM: HTTP://PORTAL.IPHAN.GOV.BR/PAGINA/DETALHES/82. ACESSO EM: 10.JAN. 2018

MUNANGA, KABENGELE. SUPERANDO O RACISMO NA ESCOLA. BRASÍLIA: MINISTÉRIO DA EDUCAÇÃO, 2005.

MUNDURUKU, Daniel. Coisas de Índio. 2.ed.São Paulo: Callis Ed.,2010.

MERLEAU-PONTY, Maurice. O ser-para-si e o ser-no-mundo. In: Fenomenologia da percepção. São Paulo: Martins Fontes, 1996, p.492-612.

SACCOMANI, Maria Claudia da Silva. A criatividade na arte e na educação escolar: uma contribuição à pedagogia histórico-crítica à luz de Georg Lukács e Lev Vigotsky. Campinas, S.P.: Autores Associados, 2016.

SOUZA, Tatiane Pereira de. Áfricas: Processos Educativos Presentes no Terno de Congada Chapéus de Fitas. Dissertação de mestrado. São Carlos: UFSCar, 2012 (no prelo). 